\title{
LEGAL, SOCIAL AND ETHICAL ISSUES IN EUTHANASIA
}

\author{
Chris O. Abakare \\ Department of Philosophy, Nnamdi Azikiwe University, \\ Ifite Road, 420110, Awka, Anambra State, Nigeria. \\ chrisabakare@gmail.com
}

\begin{abstract}
In the present era, there is tremendous changes have taken place in beliefs and practices pertaining to the beginning of life. Family planning and birth control instead of being condemned are now accepted as a duty and responsibility. Now abortion is legal in certain circumstances, if abortion could be legal in certain circumstances, then why is there no euthanasia law for the people who have no hope of their life? All human beings have the fundamental right to live. However, there is always a dilemma involved in letting the suffering people die and killing the innocent patient under a false pretext. It can be argued that the issues involved in euthanasia have a significant implication for the individuals in society and to the policymakers. Many people pray that they will not outlive their usefulness and became a burden to their next kin, forcing them to spend large sums of money only to postpone inevitable. Euthanasia is a controversial topic and people are becoming increasingly aware of the issues attached to it. Evidence of this is the question and argument being orchestrated in a rising volume of publication seminars conferences, court decisions and legislative proposal. . This work attempt to stimulate discussion and appropriate action in dealing with this present problem. This present work concentrates on the implications involved in the human rights to live especially in the field of medicine and also aims at expositing the issues of euthanasia from legal, social and ethical perspectives.
\end{abstract}

Keywords: euthanasia; Ethical Issues; Legal Perspective.

\section{INTRODUCTION}

In normal situations patients are often taken care of in normal circumstances, however, in case of the severe or final stage of a terminal disease, she /he can be either sustained forever in their own existing painful conditions or can be allowed to die. The dilemma involved in fluctuating between these two alternatives is often a crucial and debatable topic in all the ages and the ages to come. In these situations, questions can be raised from an ethical, social, legal and medical perspective which needs to be addressed in an altruistic and judicious manner. If we are about to terminate the life of an innocent patient who is in a painful condition but prefers to live then the ethical question arises; how we can take the life of others? This is against medical ethics. And another question is, whether it is ethical to keep him/her alive just because we cannot morally let him/her die? Can his/her family insist on keeping the patient alive or his/her life is not to be continued? What are the legal rights of the patient and his/ her family? What is the responsibility of the physician in providing medical care? Is it legal to discontinue the care? Can the patient herself influence the decision taken regarding her future medical care? In this work, an attempt has been made to analyse these debatable issues which form the cornerstone of this work. 
More often emphasis is placed on the medical profession whenever the question with regard to the individual's life and related issues. The difficulties arise in the case of terminally ill patients where the ethical debate over the value of life is of utmost importance. However, these ethical debates have to be viewed along with the legal scrutiny of euthanasia.

\section{EUTHANASIA FROM LEGAL PERSPECTIVE}

The constitution of law is one of the strong pillars of human society (Edor \& Odok 2010). Human beings must abide by the law to have a peaceful society. Otherwise, society will be in chaos. Unconditioned action is not free action. An action cannot be considered as free unless and until it is preceded by some necessary condition. Every action in a society can be considered either right or wrong (Akwaji \& Paschal 2018). Right action gets the approval of the society whereas the wrong action gets disapproval from the society. To prohibit the wrong action done by an individual and to protect others from being a victim of it, state laws have been framed. If an individual performs an action not approved by the society, such actions are considered as wrong actions and the state enforces laws to prevent such actions, either by punishment or by reformation. The rationale behind state's law and order is to maintain a peaceful atmosphere in our society and also to help in upholding good human relations. Hence, an attempt to problematize the dilemmas involved in legalising euthanasia as right or wrong is considered here.

Every profession as a wheel revolves with a certain ethical code as its fulcrum. It implies certain imperatives are ethical and certain imperatives are legal which is protected by the state. Medical profession in one such profession which encompasses both ethical and legal codes. Even the issues pertaining to euthanasia raises questions like: whether the physician, patient or relatives have the right to decide the application of euthanasia? It is the final decision of an individual during the last stages of his/her life, so it is of undue importance to analyse the issues involved in legalising euthanasia, so that it can be prevented from being abused. Other groups may say that there is no need for legal permission to apply euthanasia. However, if euthanasia is legalised then there may be a solution for the questions like whether the individuals or patients have the right to live or die. But euthanasia, if legalised will be abused; if it is not legalised then the patient has to undergo continued sufferings. Hence, there are ethical and legal dilemmas involved in legalizing euthanasia.

There are states which legalized euthanasia such as Belgium, Luxemburg, Netherlands, Oregon, Montana and Washington.

In Switzerland practicing active euthanasia is accepted and is legalized (Hurst \& Mauron 2003). According to it, the doctor can administer lethal injection to the patient based on his/her consent. Here, there is no guilt of a criminal act from the doctor's side. Euthanasia is not legalized in Britain (Hurst \& Mauron 2003). March 2012, survey mentions that 180 British people were administered euthanasia in Switzerland, based on their living consent. This form of death is known as 'dignitas', which means 'suicide tourism' (Lorenzl et al., 2017).

Netherland is the first country to legalize euthanasia with some terms and conditions. The rules that have to be followed by the physician in the Netherlands for practicing euthanasia are mentioned below:

1. The patient's suffering is unbearable.

2. The disease is incurable.

3. Patient's condition is terminal.

4. Patient's request for death.

In many countries the wave towards legalising application of euthanasia seems to be in an increased order. The first attempt made in the $20^{\text {th }}$ century in legalising euthanasia is by the 
Jurnal Predestination: jurnal of Society and Culture.

Vol .1 No.2, Maret 2021

United States of America. The concept of euthanasia was first introduced in the Ohio legislature in the year of 1906. But the attempt was failed due of the lack of supporters (Tarabeih et al., 2020). In the election conducted for legalising euthanasia, only 22 people voted in favour of voluntary euthanasia out of 78 , subsequently the bill was rejected and the idea of voluntary euthanasia was dropped. The attempt to legalise euthanasia has both positive and negative sides. Few groups rejected and few other groups accepted the legalisation. Most of the people from the religious groups rejected the application of euthanasia and a portion of doctors also rejected it. The acceptance or rejection mainly depends upon the culture and moral norms of that country.

\section{ARGUMENTS FOR LEGALIZING EUTHANASIA}

Euthanasia helps for living with minimum dignity as well as it respects the patient's rights. This can be considered as a right to self- determination or a right for privacy of the patient or individuals. The right of individuals is "a right to determine the time and manner of one's death, 'the right to die, a liberty to choose how to die', and liberty to shape death" (Glenn 2003, p. 173).

The legalisation of the euthanasia is applicable only if:

1. The person is facing terminal pain

2. Patient is conscious and are able to take a decision

3. At least two or more physicians certify that he cannot lead a normal life.

4. The death of the patient should not be to grab property or relieve the burden.

If the physician, even after giving the best treatment, can't bring the patient back to his real life, then what is the need of suffering? If there is a chance to lead a normal life, suffering is not that much problem for patients. If he is going to die within a month, then an early death implies an early relief from the sufferings. The second point is that, the patient will take a voluntary choice of euthanasia because it is their own life. So they have to make a decision. The patients have the right to choose whether to live or die. If the patient takes the decision, it will be their autonomous choice and individual dignity. The autonomy and dignity of the patient will be a voluntary choice of their life.

The third point is that not only one physician but at least three physicians have to certify that the patient has no scope of recovering from the current position. If it was done by the physicians stating that the patient cannot come back to his normal life then it is feasible to apply euthanasia. The fourth condition; in most cases euthanasia is applied without the consent of the patient. The aim of the relatives may be different. The relatives will be worried about the expenses of the treatment in case of patients in old age. In this situation, relatives think that he lived enough and his time is almost over. The money spent on him will be of no use, so they recommend applying euthanasia.

Other conditions for the application of euthanasia are;

1. Person is suffering a terminal illness;

2. Is likely to benefit from the discovery of a cure for the illness during what remains of his life expectancy;

3. Is, as a direct result of the illness, either suffering intolerable pain, or an unacceptably burdensome existence(because the illness has to be treated in ways which make him so dependent on others, or on technological means of life support, as to cause severe distress);

4. Has an enduring, voluntary and competent wish to die, or, in the event that he is no longer competent, has previously, while competent, given appropriate expression to his desire to die should condition 1-3 be satisfied; 
Jurnal Predestination: jurnal of Society and Culture.

Vol .1 No.2, Maret 2021

5. Is unable, without assistance, to commit suicide (Young 2007, p. 17).

The argument for legalising euthanasia can be divided into two: moral and material. The moral is the painful life of the patient and material is the financial problem. Glanville Williams introduced the moral part of legalising euthanasia. In his point of view the term 'cruelty' was the moral name. If we won't legalize euthanasia then the patient will suffer with unbearable pain. In his view "cruelty is an evil" (Pojman 2000. p. 224). Here, we are doing cruelty to the patient. In other words by legalising euthanasia we can rescue the terminally ill from the cruelty. Here, we can permit their wish without any legal consequences. When the patient who suffers with terminal illness or in comma, if we allow the patient to live then it is a cruelty towards the patient. Here, cruelty comes from the relatives and physicians when they know that the patient will live only for two or three months. So allowing the patient to live is cruel in such situations. In this situation, if the physician is rejecting the patient or his relative's request then he is doing cruelty to the patient.

Another way of cruelty is the lack of consideration for the patient's life value. It means the agony of the patient's condition will become the painful sight for the relatives. In this situation also euthanasia is preferred. Sometimes the relatives take care of the patient but he may not recover from the disease. The relatives like mother, wife and husband whoever is spending time with the terminally ill person because of the tension and emotional feelings; they may not take proper care of themselves. Because of this tension, relatives also fall ill. This will affect them mentally or physically. In this situation the patient will think about their dear one's suffering. So in specific cases the patients knowingly accept euthanasia for the sake of their relatives. If euthanasia is accepted the suffering of the patient can be reduced. Both the patient and relatives are in pain and there don't be any reason to reject euthanasia. If euthanasia is rejected implies cruelty to the patient and also to his relatives. So it is better to save the life of the relatives and reduce the pain of the patient through legalising euthanasia. The third point is liberty. If a patient is suffering from severe pain, physician does his best but can't reduce his patient's pain and he finally identifies that there is no possibility of coming back to the real life. In this situation the physician executes euthanasia along with the consent of the patient. It shows the autonomy and dignity of the patient.

An individual's liberty is the fundamental freedom of the individual. Individual has the right to choose with regard to his body in the name of individual right. But this right should not harm others. Steve Dasbach, Libertarian Party Chairman of America viewed the individual's right as:

the right to life, liberty and the pursuit of happiness includes the right to die with dignity" and the power to decide how and when to die should resides solely with the individual patient, not with doctors, family members- and especially not with government (Byars and Stanberry 2019, p. 64).

In some cases of legalisation, euthanasia is favouring the patient's right and wish. It will be helpful to reduce the patient's pain and sufferings. So in legalisation, patients will fulfil their wish. They don't have to burden their relatives and they can give a solution to the financial crisis of their family members. One of the Supreme Court advocates Prashanth Booshan partially accepts euthanasia and he said that it is high time to legalise euthanasia. He said that, if the patient has already written a living will, then based on the living will of the patient we can apply euthanasia to that patient. A living will means a will written by the person who is well with a functional mind. When his health becomes worse then the physician or relatives can apply euthanasia. He also said that "the time has to come to for us to legalise euthanasia is will with sufficient case of course" (Byars and Stanberry 2019, p. 65). Living will is defined as the "written directive by an adult patient authorising withhold or withdrawal 
Jurnal Predestination: jurnal of Society and Culture.

Vol .1 No.2, Maret 2021

of extraordinary life- sustaining procedures" in the situation of "terminal illness" (Byars and Stanberry 2019, p. 66). However, But it is not possible in the case of children or others where the immediate consent is unavailable.

\section{ARGUMENT AGAINST LEGALISING}

The critics of euthanasia define that it is not right to die or right to kill. If euthanasia is legalised then people will get permission to kill the elderly and the sick people. If they don't want to die, then the relatives will kill in the name of euthanasia. Here the innocent people will die unnecessarily. Sometimes it is against the patient's wish to live along with pain. But the argument against legalisation forces the patient to live although he /she doesn't wanted to. Here the patients will suffer with severe pain. This is not the correct application of individual's right. It is against the individual's right. Sometimes the legalization of euthanasia will be misused. If the relatives want to grab property, they will kill the patient in the name of euthanasia. Nobody has the right to kill others. But if euthanasia is legalised they will kill other innocent people. Sometimes, in the cases where the patients are old people the relatives will apply euthanasia and kill innocent people, though the patient may have a desire to live but at the same time they may not like to be a burden on the relatives. If we don't legalise euthanasia it will be a problem to the individual's privacy. The patient's intention of not being a burden to others will be against the patient's wish and right. In this situation the individual has to live for the other's wish, not only for his own wish. The law for legalisation of euthanasia sometimes becomes the reason for death of the innocent patients. According to the religious view, it is not a right to die but it is right to kill.

Christianity is the main religion which has arguments against euthanasia. Because their concept is that life is a gift of god, so god has only the right for taking life back. The omnipotent, omniscient and omnipresent God only has the right to take the life. Life is the image of God. Human beings don't have the right to interfere in God's plan. The whole life is the image or creation of the God. They believe that the patient with a head injury, comma stage and some other severe disease need not go for euthanasia. By providing life system as a support sometimes the patient, they will miraculously return back to the real life. So, in this context euthanasia is unjustifiable. This view rejects euthanasia. The partial group of physicians and philosophers like Jack Kevorkian accept euthanasia. In their view, there is a possibility of recovering from disease in future. So the societies as well as others also don't have any right to kill. The religious views are against euthanasia. The non- religious views that there is no possibility of the person coming back to the real life. But it can't be ruled out that the patient can come back to the life miraculously.

If euthanasia is legalised, it will affect the medical profession. If euthanasia is practiced, then people wouldn't trust the physician. Whatever the treatment provided to the patient, they won't believe the physician. In other words the physician gives better treatment to his patient along with care, instead of killing the patient. Right now healthcare institutions and hospitals work only for saving the people's life. Once euthanasia is legalised they will become killing centres, and the medical profession will start malpracticing. The medical profession and healthcare centre's duty is saving the life. If euthanasia is legalised gradually they will forget their duties of saving lives. Euthanasia is not legalised yet in Nigeria because generally we give importance to our family and we are emotionally attached to each other. The main reason against the legalisation is that "in Nigeria where emotions and culture played a major part and we have strong social values" (Ogar \& Ogar 2018, p. 38). Once euthanasia is legalized it will lead to wrong practices. Because of this many innocent people may die. 
Jurnal Predestination: jurnal of Society and Culture.

Vol .1 No.2, Maret 2021

\section{SLIPPERY SLOPE ARGUMENT}

It is defined as the good intention will be a reason for the bad intention of similar case. Euthanasia if legally permitted, would lead to a general case of taking human life. If we accept mercy- killing or euthanasia to the requested person based on the patient's agony along with our honourable motive and result might be good then this will abuse the healthy person for bad motive. Once euthanasia is legalised there is a chance for the practice of cold blooded murder likely to happen continuously in minute case. Bishop Sullivan's argument about the legalisation of euthanasia is:

To permit in a single instance the direct killing of an innocent person would be to admit a most dangerous wedge that might eventually put all life in a precarious condition. Once a man is permitted on his own authority to kill an innocent person directly, there is no way of stopping the advancement of that wedge. There exist no longer any rational grounds for saying that the wedge can advance so far and no further. Once the exception has been made it is too late; hence the grave reason why no exception may be allowed. That is why euthanasia under any circumstances must be condemned (Rachel 1986, p. 171).

The slippery slope argument is against legalising euthanasia because there is a chance for abusing. The legalising of euthanasia is for saving the patient from the unwanted burden of the incurable disease. "The slippery slope argument holds that if a proposal is made to accept $\mathrm{A}$, which is not agreed to be morally objectionable, it should nevertheless be rejected because it would lead to B, which is agreed to be morally objectionable" (Keown 2018, p. 71). This will amount in the application of death of an innocent or healthy person. Slippery slope argument says that doing something with a good intention is the reason for another bad thing.

In most of the case, people are against the legalisation of euthanasia. They are thinking of intentionally to take the life of other person, is wrong. The slippery slope argument is wrong "sometimes has force, and sometimes lacks force" (Keown 2018, p. 72). By legalising euthanasia it gives relaxation to kill the terminal patients as well as the normal patients. So "many people oppose the relaxation of the law because they believe it would result in two undesirable consequences" (Keown 2018, p. 70). Dr. John Habgood, member of the House of Lords Select Committee on Medical Ethics and also Archbishop in New York wrote about the legislation of euthanasia in 1974 "legislation to permit euthanasia would in the long run bring about profound changes in social attitudes death, illness, old age and the role of the medical profession" (Keown 2018, p. 71). The legalisation of euthanasia will benefit to the competent patient in some certain situations but it is the reason to the death of incompetent patient. In brief, legalisation of euthanasia is not only the termination of life, but also in the decision to terminate life" (Keown 2018, p. 65).

If euthanasia is legalised, then there is a chance of abusing this practice. If the justice of the country gives permission to the terminally ill person it may kill the normal person also. So legalising euthanasia is not acceptable. Various problems related in legalising euthanasia are:

1. If voluntary euthanasia was to be legalised it would prove impossible to avoid the legalisation, or, at least, toleration, of nonvoluntary euthanasia. But, even if the former can be justified, the latter clearly cannot. Hence, it is better that the first step (legalising voluntary euthanasia) not be taken so as to prevent a slide into nonvoluntary euthanasia.

2. If voluntary euthanasia were to be legalised it would signal society's approval of medically assisted death as a means of escape from life's difficulties and so would open the floodgates to requests from people not suffering from a terminal illness who want to be assisted to die while they are relatively healthy, because they dread having to face a problematic future existence (perhaps, for example, because of having been diagnosed 
Jurnal Predestination: jurnal of Society and Culture.

Vol .1 No.2, Maret 2021

with Alzheimer's disease), or because they are depressed, or disabled, or just feel excluded from their community. To avoid any such slide, society should resist the legalisation of voluntary medically assisted death and, instead, provide those who request it with the support necessary to enable them to make decisions free from the effects of socially coercive forces (like lacking access to adequate resources, or being victims of social discrimination).

3. If voluntary euthanasia was to be legalised it would result in abuse or neglect of the vulnerable, and mistakes in the treatment of patients. So, whatever the merits of legalising voluntary euthanasia, it would inflict a terrible cost via the resultant abuse, neglect and mistaken killings. Since the costs to be borne by the abused, neglected and mistakenly killed would outweigh the benefits to be had from legalising voluntary euthanasia, it would be foolish to legalise it (Young 2007, pp. 178-179).

The above mentioned arguments are against legalisation of euthanasia or slippery slope argument. If euthanasia is legalised then there is a possibility for physicians violating their duty. Permission from the legislation to the terminally ill patient sometimes the case filed by the court will be either from patient side or from the relative's side. The patient knowingly approaches the court for applying euthanasia e.g. Ifiok's case. Then, if the legislation gives permission to that patient sometimes this can be taken as the base behind the comma patient's death e.g. Aruna's case. In the first case Ifiok knowingly approached the court for euthanasia with the help of his mother. It shows the intention of the patient. But in Aruna's case her friend approached the court without her concern. So it shows that here the intention of the patient is abstract. So there is a possibility for different situations. The slippery slope argument gives chance to the patient more than the legal permission. So this will be made change to patient's death from the "better off dead" (Grisez \& Boyle 1979, p. 173) to become a "better of killing". Thus the society, medical profession and relatives also have a chance for doing corruption. So legalising euthanasia is wrong. There are two face of philosophical argument against the legalisation of euthanasia.

The two forms of slippery slope argument: logical and empirical. Logical argument of slippery slope is taking decision on the logical judgement. If the legislation gives permission to the physician, he will analyse what is right or wrong. He is not a robot or a mindless person. So he will have his own judgement about the merits and demerits of the medical intervention. Apart from this, the logical slippery slope argument is defined as;

If no significant conceptual difference between $\mathrm{X}$ and $\mathrm{Y}$ can be identified, the justification used to support $\mathrm{X}$ will also support justification for $\mathrm{Y}$, if $\mathrm{Y}$ is unacceptable, $\mathrm{X}$ should also be unacceptable due to its lack of conceptual distinction from Y (Paterson 2008, p. 73).

Here imagine $\mathrm{X}$ and $\mathrm{Y}$ are the identical twins, they are lying side by side along with the identical painful terminal illness and suffering is same for both. The consulting physician is also same. Here $\mathrm{X}$ is a conscious patient and $\mathrm{Y}$ is unconscious. The legislation gives permission to $\mathrm{X}$ for applying euthanasia. So this permission also equal to the $\mathrm{Y}$. The justice gives permission only for the $\mathrm{X}$ but it can be apply to the $\mathrm{Y}$ also. The logical slippery slope argument rejects legalising euthanasia. "The logical form of the slippery-slope argument does not work in the case of euthanasia; and so it does not provide good grounds for thinking that euthanasia ought to be legally prohibited" (Rachel 1986, p. 172). The legalisation of euthanasia to the terminal patient is logically ought to support incompetent patient. The logical form of argument is "once a certain practice is accepted, from a logical point of view we are committed to accepting certain other practices as well" (Paterson 2008, p. 173). 
The empirical slippery slope argument "takes the form of the likelihood of X sliding towards $\mathrm{Y}$ due to the operation of psychological, cultural and social factors that will erode boundaries between X and Y" (Paterson 2008, p. 173). It impliesthat there is no boundary between legal and illegal for practicing euthanasia. Sometimes it will be practiced against the empirical features like psychological, cultural and social. Euthanasia is performed to the patient based on the clear request form the patient side. It cannot be performed prior consent of the patient. The empirical argument of the slippery slope is that, the doctor may fail to get approval from the patient. Sometimes the relatives may demand the patient to make the request. Where the physician will fail to understand whether the request is ethical or not. In such instances legalising euthanasia may pave a way for misuse. Some physicians may fail to identify the genuine request because, although they are conscientious practitioners with the best interests of their patients at heart, they lack psychiatric expertise in taking decision. Others will fail because, although they may have, the theoretical access to the required expertise, but, they lack the time or resources to apply it in practice.

The lawyer and philosopher, Daniel Callahan's view on legalizing euthanasia aims at protecting the physician and there by hampering the well-being of the patient. It will not, and cannot, achieve the goal of protecting patients or of preventing or limiting abuse. If protection of patients and meaningful regulation of PAS/euthanasia is the goal, no legislation can achieve it (Callahan, \& White 1996).

\section{EUTHANASIA FROM A SOCIAL PERSPECTIVE}

Euthanasia as a social issue has its influence on cultural, economical and political aspects. It reflects on the liberty of the society. Socially the individuals have some fixed values and norms and the individuals have to follow those morals in a society. The dying person and the relatives of the patient also have to follow certain social norms and values. Even though, the patient is suffering from painful disease and distress; his relatives have to consider the social norms. In any society there are some beliefs about the individual's life, which can't be overruled. In this situation, if euthanasia is legalised it will lead to social controversies. The loved one's suffering and distress will be a painful sight to the relatives, but from the legal perspective there is no place for the moral norms and values. A good number of old age homes, homes for rehabilitation centres and mentally challenged have been emerging in the contemporary society. The brutality and barbarian form of living existed during the precivilization period might creep in the existing situation there by warns about the difficulties in administrating euthanasia which will create a chaos in the society. In this context ethical problems will arise in mercy killing.

When euthanasia is legalised the patient's autonomy will be in trouble. Where in there will be inequality in autonomy when the relatives demand the patient to die. Which will inturn, directly or indirectly reflects on the patient's existence. Psychologically, they will be frustrated. Good family and society is the base of individual's good action and support. It includes emotional, practical and financial support of the individual. In near future, there might be a situation where human beings will be considered as mere specimens in conducting laboratory experiments in the name of euthanasia. In this way, euthanasia will open the gates in letting the social evils to its abuse and threat, for the human existence in the society.A clear discussion pertaining to euthanasia is important in this perspective. The same case can be viewed from a sociological point of view.

Thalaikoothalis a social practice behind which there is a motive in killing the elderly people (Pousset 2018). In Tamil Nadu, Virudhunagar district and some other southern parts of Tamil Nadu there is an established social practice named thalaikoothal. This is applied on 
Jurnal Predestination: jurnal of Society and Culture.

Vol .1 No.2, Maret 2021

the elderly or to the terminally ill people. These elderly people are given a ceremonial oil bath, after that they will be fed tender coconut water. Which will cause pneumonia and eventually lead them to death. Sometimes they will add poison for hastening the death. Their main motive will be to grab the property. One such incident was reported in Virudhunagar district. Where an eighty year old man escaped from his house because his children were going to conduct the thalaikoothal functions for him. The whole family members were involved in the unethical social practice. This in turn implies that if euthanasia is legalized, there is a possibility of misusing them on the innocent people without any shadow.

Lack of awareness is the first reason for misusing euthanasia and majority of the people don't have the knowledge about euthanasia. Some people are not educated and also they are exploited in specific situations. Sometimes patients seem to be a burden to the relatives, so they will apply euthanasia without the edge of the patient. The patient may not be aware of what is going to happen and he may die unknowingly. The aim of the relatives may be grabbing the property and reliving from the burden. Because of these reasons the poor individuals lose their life. According to Dr.AmitAgarwal, oncologist of Fortis Hospitals Noida Delhi, India expressed about his dilemma of the lay man's awareness of euthanasia as;

Absolute lack of public awareness and clear- cut legal directions on end- of- life terminal care. Whenever we are in a situation where nothing is going to be advice by aggressive, life sustaining treatment in a terminal ill patient, we honestly tell the patient and the family and take in to consideration what the patient would have wanted. We also do everything to make the patient as comfortable and pain- free as possible (Umasekar 2010, p. 6).

Euthanasia is not only a legal and ethical issue but a social issue also. Social issues are discussed by Lord Brock (London). He did not oppose euthanasia but analyses the sociological perspective of euthanasia. Once euthanasia is legalised, the government will face the problem of applying euthanasia because the government is supposed to solve the problem after legalizing euthanasia. The government encounters the challenges like: Who will perform euthanasia? Where will it be practiced or where will we practice it, home or hospital? How should be done? Lord Brock hoped that the doctors and nurses would not do this because they have the duty to save a patient's life and not to kill.

In social life it is often considered as a burden for the family and the individual, when it comes to the case of a diseased and disabled person. So their life will become devalued and they will be a burden to their relatives. They themselves feel that they are burden to their relatives and also to the society. Because of the helplessness in life they think that they are not useful to the society. Since their life is not valuable, they are forced to die. Here, the patient's autonomy is of no value since the final decision is taken by the relatives. Society is always concerned about the individual's quality of life. So society has the responsibility of protecting and giving them good quality life. Sometimes society also fails in this aspect. The diseased person will be facing more psychological pressures. So the best option is to choose death. Death is the only way of escaping from the intolerable situation and also from the suffering of painful disease. Here, the patient may opt voluntarily or knowingly but not with 'coercion'.

The government and the society have the responsibility to secure the life of disabled persons. Some special shelters have to be allotted for the disabled people. But this will make isolation of the disabled people for instance in the case of AIDS patients. Once society starts isolating the AIDS patients, it will become practice. People still think that AIDS is a vulnerable disease. This isolation will detach the connection between ordinary man and the patients. This type of isolation will affect the patient psychologically. So they will think that there is of no hope of recovering, and they will be depressed and forcefully take the decision for applying 
euthanasia. But the society also has the responsibility to help the isolated patient. This isolation of the patient or elderly people motivates them for dying. The society has the responsibility to protect the elderly people. One such isolated place is an old age home.

The painful sight of the patient will create sadness in the life of their close relatives due to the lack of emotional support and financial support so only a good family can produce good individuals to the society. The emotional attachment of the family members will create worries to the disabled person. It will be one of the reasons for choosing euthanasia by the patient. The question is who will perform euthanasia? Usually doctors practice it in some circumstances. Sometimes based on the patient's request, others might perform euthanasia. But once euthanasia is legalised, a dilemma will be opened. Applying euthanasia can be justified under some circumstances in the medical field. But in society it is wrong. If many people want to apply euthanasia it leads to many controversies. The government has to identify specific place to perform euthanasia hospital or some other place. If someone kills the other person for the sake of property, the government will not be able to sentence that person. Since it has legalized killing and cannot punish the people. All these types of dilemmas are to be encountered by the government.

Nigeria, have some social, culture and ethical norms. These are norms binding our law. If this type of killing gets permission from the law then nobody wants to practice it. In Nigeria euthanasia cannot be reformed to the patients. It is a social problem. The government has to appoint doctor and police for killing. It implies killers are also needed in our society. If euthanasia is legalized socially it will be misused. In the name of euthanasia the patient will be exploited for the sake of organs. The world we are living is turning out to be more materialistic, selfish and detached where everyone is looking forward only for the money and nobody bothers about love and emotional feelings like bonding and attachment. In the present context there is a possibility of killing a PVS patient or brain dead patient for the aim of removing the organs and we know that such cases have been reported in the third world countries and especially in a country like Nigeria where population is beyond control and poverty is found everywhere.

The main trouble which the society will be facing is the difference between haves and have-nots. There is a chance for killing the have- not people for many purposes. In the contemporary world many people are living on foot path. The government and society also don't accept them as citizens. Some time they may be killed for the political reasons. The societies should give importance to the progress of the rehabilitation centres for old people, for children, for patients and mentally challenged persons. The people also should feel responsible along with the government. If euthanasia will be practiced, then there is no need of any values in the society. In Nazi Germany, euthanasia was practiced for killings the people with disease. Once euthanasia is legalized, then it is good to any society. Perhaps Hitler's aim was to reduce the economic burden but here the aim is different.

At the same time both for the relatives and for the medical institutions, the patient becomes a burden. In these circumstances, the physician advises to relatives to take back the patient. If relatives give the plea to the institution, then they can allow the patient to stay in the hospital. Here, both the relatives and the institution may feel the burden. One of the reasons is financial.

\section{PERSPECTIVE IN FAVOUR OF EUTHANASIA AS UNETHICAL}

Ethics is the judgement of human actions, an action which is right or wrong will be decided according to the context in which the action needs to be taken (Nwoye 2018). Here, ethics become relative and situational. According to Joseph Fletcher's, ethics deals with 
Jurnal Predestination: jurnal of Society and Culture.

Vol .1 No.2, Maret 2021

preferable and science deals with possible and probable. Ethics is the moral action of human beings in the society in which they are situated. Ethics can be applied only in the sphere of the homo sapiens and not among the animal sphere or divine sphere. Society is made up of some rules and regulations (Ogar and Ogar 2018). These rules and regulations are part of ethics, helping the human beings to make their character good (Esikot et al., 2019). Every individual is imbibed with some ethical qualities one way or the other, even a criminal does not lack ethics. It is highly impossible to ignore ethics from the human sphere which is the fulcrum of the human institution. For instance in the field medicine, the professional code of ethics forms the completeness of that profession, where the doctor's prime duty is to save life, which is reflected in the Hippocratic Oath (Askitopoulou \& Vgontzas 2018).

In the current world people have not given preference to the morality and they are living in their own life style with their own concepts without morality. They are thinking about their own ways of establishment. They are killing others for the selfish purposes. They don't bother about the other peoples mind and problems. Killing other people for selfish purposes and applying euthanasia is wrong or unethical. Every human being has a natural tendency for long life along with his dear and near ones. At the same time if they are suffering with any incurable disease they will be the burden for their family. The patient will be thinking about the family's financial situation also. So in such cases they will be opting to die. Euthanasia appears to be the best possible solution for such patients. One of the cases described below will explain the above mentioned situations.

The religious view says that, euthanasia is unethical because their belief that the life is created by god. So taking the life back is the sole right of God. So if we kill the person or the life, or the destruction of life then it is the rejection of a divine gift. Religion says that we have no right to take the life but we have duty to live the life till god takes our life back (Allam 2018). Religion believes that we have right to live. The religions believe that sometimes the patients who are in a vegetative state due to head injury or any other brain disease are not surefine cases for euthanasia. For these comatose patients' if proper medical care and life support system is given few months, they will be miraculously swung back to recovery and resumed life so the religious are doctrines for applying euthanasia. The religious dictum like 'Do not steal' 'Do not kill' and 'Do not tell a lie'. This is the most important ethical judgment. The religious and ethical systems upholds the concept of ethics and the religious thinkers also telling it's not good because our life is gift of god so we have no right to take life.

\section{CONCLUSION}

The point which I am trying to drive home from this work is that after analysing pros and cons of euthanasia from legal, social and ethical perspective, it is clear that that it is very hard to generalize whether euthanasia is right to wrong. There is always an ethical dilemma involved in deciding whether it is good or bad, finding a general or absolute solution is a farfetched idea this work. However, that doesn't mean that it is not in a position to analyse it, balancing with the merits and demerits of euthanasia, it seems to me that euthanasia has to be viewed with the spectacles of three sixty degree. The lived experience of patient along with the environment in which he is situated should be the yardstick in deciding the merits and demerits of euthanasia. Above all according to the situation and the context in which the problem arose has to be viewed from different angles before taking any decision, in this context it has to be viewed from medical grounds, legal, social and ethical grounds before taking any decision. Such a solution will be rational as well as ethical and also a path finder. 
Jurnal Predestination: jurnal of Society and Culture.

Vol .1 No.2, Maret 2021

\section{REFERENCES}

Allam, O. S. (2018). Unmasking "Alekwu" Religious Experience among the Idoma PeopleGroup of Nigeria. GNOSI: An Interdisciplinary Journal of Human Theory and Praxis, 1(2), 118-130.

Askitopoulou, H., \& Vgontzas, A. N. (2018). The relevance of the Hippocratic Oath to the ethical and moral values of contemporary medicine. Part II: interpretation of the Hippocratic Oath—today's perspective. In European Spine Journal (Vol. 27, Issue 7, pp. 1491-1500). https://doi.org/10.1007/s00586-018-5615-z

Byars, S. M., \& Stanberry, K. (2019). Business ethics. Houston, TX: OpenStax College, Rice University.

Callahan, D., \& White, M. (1996). The legalization of physician-assisted suicide: creating a regulatory Potemkin village. U. Rich. L. Rev., 30, 1.

Esikot, I. F., Bessong, P. K., \& Ette, E. E. (2019). An Examination of Spinoza's Moral Philosophy. GNOSI: An Interdisciplinary Journal of Human Theory and Praxis, 2(1), 10-19.

Glenn, R. A. (2003). The right to privacy: Rights and liberties under the law. Abc-Clio.

Grisez, G. G., \& Boyle, J. (1979). Life and death with liberty and justice (pp. 59-85). Notre Dame: University of Notre Dame Press.

Hockey, L. (1987). The End of Life: Euthanasia and Morality. Journal of Medical Ethics, 13(1), 50.John Keown, J. (2018). Euthanasia, ethics and public policy: an argument against legalisation. Cambridge University Press.

Hurst, S. A., \& Mauron, A. (2003). Assisted suicide and euthanasia in Switzerland. BMJ, 327(7405), 52-53. https://doi.org/10.1136/bmj.327.7405.52-c

Lorenzl, S., Butzhammer, L., \& Nübling, G. (2017). Assisted Suicide of patients with parkinsonian syndromes in Switzerland - the need of early and continuous integration of palliative care and dignitiy therapy. Movement Disorders, 32(suppl 2).

Nwoye, L. (2018). A Critique of Hume's Ethical Empiricism: Towards Addressing Ethical Dilemmas in Making Moral Choices. GNOSI: An Interdisciplinary Journal of Human Theory and Praxis, 1(2), 9-14.

Ogar, T. E., \& Ogar, J. N. (2018). Globalization in Africa and Beyond: The Quest for Global Ethics. GNOSI: An Interdisciplinary Journal of Human Theory and Praxis, 1(2), 38-47.

Paterson, C. (2008). Assisted suicide and euthanasia: a natural law ethics approach. Ashgate Publishing, Ltd.

Pojman, L. P. (2000). Life and death: a reader in moral problems. Wadsworth Publishing.

Rachels, J. (1986). The end of life: euthanasia and morality. New York: Oxford University Press.

Tarabeih, M., Bokek-Cohen, Y., Abu Rakia, R., Nir, T., Coolidge, N. E., \& Azuri, P. (2020). Religious observance and perceptions of end-of-life care. Nursing Inquiry, 27(3). https://doi.org/10.1111/nin.12347

Umasekar, S. (2010, February 14). The Fight for Dignity in Death. The Hindu Daily News Paper, pp. 1-19.

Young, R. (2007). Medically assisted death. Cambridge University Press..

Young, R., Van Beinum, M., Sweeting, H., \& West, P. (2007). Young people who selfharm. The British Journal of Psychiatry, 191(1), 44-49. 